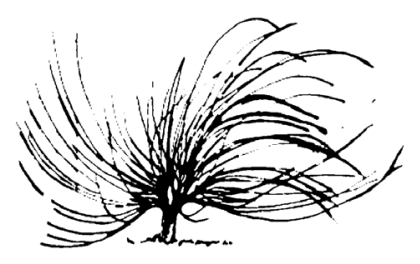

\title{
La transmisión inconsciente en la cultura y la educación
}

\author{
Mónica Morales Barrera ${ }^{l}$ \\ Facultad de Estudios Profesionales Aragón (FES Aragón) \\ Universidad Nacional Autónoma de México UNAM \\ México \\ monicamoralesba56@gmail.com
}

\begin{abstract}
Resumen
La palabra transmisión es frecuentemente utilizada en nuestra habla cotidiana como un simple sustantivo y la encontramos acompañada de otras que le dan contexto, por ejemplo: enfermedades de transmisión sexual, transmisión televisiva, transmisión de calor, transmisión de datos, etc., aquí es tangible distinguir lo que se transmite y predecir posibles resultados; en cambio si se estudian las particularidades de la transmisión inconsciente entramos en terrenos movedizos, en tanto es un fenómeno imperceptible, cuyos resultados no son posible controlar. El propósito de este ensayo es explorar este peculiar mecanismo que comparten dos ámbitos concatenados que son la cultura y la educación. El ensayo aborda ejemplos que consideramos paradigmáticos para estudiar la transmisión inconsciente, por lo que va más allá de cualquier propuesta histórica o antropológica. Igualmente, se proponen diferencias conceptuales entre otros fenómenos aparentemente similares como lo son la comunicación y la enseñanza; haremos especial énfasis
\end{abstract}

\section{(c) $(\Theta \Theta$}

Recibido: 26 de marzo de 2019. Aprobado: 12 de setiembre de 2019.

http://dx.doi.org/10.15359/rep.14-2.5

1 Dra. en Pedagogía por la Universidad Nacional Autónoma de México (UNAM) y Mtra. en Teoría Psicoanalítica por el Centro de Investigaciones y Estudios Psicoanalíticos (CIEP), profesora de tiempo completo en la licenciatura de Pedagogía de la FES Aragón, UNAM. ORCID https://orcid.org/0000-0002-9830-5835 
en el muy afamado preconcepto sobre la transmisión de los conocimientos, pues ya desde Platón se anticipa su imposibilidad. Finalmente, al tema de la transmisión inconsciente en la cultura y la educación se liga al de la ética, pues se va tomando conciencia del poder de la palabra inintencionada en la formación de los educandos.

Palabras clave: transmisión inconsciente, educación, cultura, psicoanálisis.

\begin{abstract}
The word transmission is often used in our daily speech as a simple noun, and we find it accompanied by others that give it context, for example, sexually transmitted diseases, television transmission, heat transmission, data transmission, etc.; here it is tangible to distinguish what is transmitted and predict possible outcomes; On the other hand, if we study the particularities of unconscious transmission, we enter loose terrains, as it is an imperceptible phenomenon, whose results can not be controlled. The purpose of this essay is to explore this peculiar mechanism shared by two concatenated areas that are culture and education. This essay addresses examples that we consider paradigmatic to study unconscious transmission, which goes beyond any historical or anthropological proposal. Likewise, conceptual differences are proposed between other apparently similar phenomena such as communication and teaching; we will make special emphasis on the very famous preconceptions about the transmission of knowledge, because since Plato its impossibility is anticipated. Finally, the issue of unconscious transmission in culture and education is linked to that of ethics, as awareness is gained of the power of the unintentional word in the training of learners.
\end{abstract}

Keywords: unconscious transmission, education, culture, psychoanalysis 


\section{Introducción}

$\mathrm{L}$

a palabra transmisión es frecuentemente utilizada en nuestra habla cotidiana como un simple sustantivo, la encontramos casi siempre acompañada de otras que le dan contexto por ejemplo: enfermedades de transmisión sexual, transmisión televisiva, transmisión de calor, transmisión de datos, etc. aquí es tangible distinguir lo que se transmite y predecir los resultados; en cambio si se estudian las particularidades de la transmisión inconsciente entramos en terrenos movedizos en tanto es un fenómeno imperceptible, cuyos resultados no son posibles de controlar, además lo importante en este proceso no está en los contenidos que se quieren transmitir, sino en lo que efectivamente se transmite, independientemente, de su valor ético-moral.

El propósito de este escrito es explorar la transmisión inconsciente, mecanismo que comparten, a saber, dos ámbitos concatenados que son la cultura y la educación; igualmente, se proponen diferencias conceptuales entre otros fenómenos, aunque imbricados, que ocurren en el registro de la conciencia como lo son la comunicación y la enseñanza. La comunicación desde su etimología proviene del latín comunis que significa "común", poner algo en común entre los seres humanos. A la enseñanza la ubicamos como un acto intencionado a cargo de las instituciones educativas bajo los cánones que impone una civilización en particular.

La transmisión inconsciente, desde el punto de vista psicoanalítico, se concibe como un fenómeno que ocurre más allá de la conciencia de los sujetos, como un acto inintencionado, espontáneo, no controlable, ni por el emisor, ni por la comprensión intacta del receptor, pues no se trata de un proceso de repetición o reproducción, sino en el que intervienen verdaderas transformaciones psíquicas de reinterpretación, rememoración, según sean las estructuras clínicas, de impasses socioculturales, de avances tecnológicos, etc.; es en este movimiento incontrolable, donde se desarrolla la transmisión inconsciente. Por su parte Laurent Cornaz, define la transmisión como "esa filigrana que vincula a los hombres, más allá de la muerte, más allá del nacer [...] es aquello que liga sin que lo sepan a los hombres y a las generaciones, y actúa subterráneamente sobre la conducta humana" (1994, pp.17-18).

Sin embargo, en el fenómeno de transmisión hay una invariante psíquica que sostiene todo el proceso y que sin duda incide en el 
comportamiento humano. Lo transmitido se inscribe en el sujeto, desde la cuna a partir del significante del deseo del Otro. Para el psicoanálisis lacaniano el Otro (con mayúscula) es una instancia intrapsíquica, que define al sujeto como tal a partir de la relación que establece con el Otro. El Otro es un lugar que es ocupado en primera instancia por la madre y posteriormente, por otros personajes como el padre, los hermanos y los ideales. Por supuesto, el énfasis se coloca en la función que cumple, pues es en esta relación, donde se conforma el deseo del niño (cfr. Dictionnaire de la Psychanalyse, 1993). Por ejemplo: una niña de 5 años, que vivía con su madre en un centro penitenciario para mujeres, quería ser "prostituta", porque su madre le había dicho que se ganaba buen dinero; o bien la niña de 4 años que quería viajar a París, porque escuchaba a su abuela, en el lugar del Otro, que quería hacerlo.

La transmisión inconsciente, sin duda, incide de manera intangible en la conducta, decisiones y elecciones de cada uno de los seres humanos, anticipando la manera como el sujeto participa en el mundo y que dejará una huella distinta en su conformación psíquica. La transmisión es lo que subyace en los enunciados de padres de familia, docentes o del poder soberano en boga, es aquello que se dice de manera espontánea, alusiva, en los lapsus, en lo que no se quería decir, pero se dijo.

Tanto, la cultura como la educación comparten los modos de transmisión inconsciente, cuyo mecanismo ha sido desestimado en aras de la objetividad.

\section{La transmisión en el campo de la cultura}

A diferencia de la herencia genética instintual, la transmisión constituye el medio a través del cual el ser humano crea una herencia cultural; el sapiens es el único ser que posee la aptitud para transmitir y también crear. El hombre de cultura conserva huellas mnémicas de antepasados, inventa en la medida en que almacena, deja rastro en el mundo y lo hace a partir del lugar y el tiempo en que le tocó vivir, de ahí que las civilizaciones construyan grandes monumentos arquitectónicos, preserven tradiciones, abriguen religiones. Incluso el trivial acto de dejar grabada en un árbol la leyenda "aquí estuvo Juan Pérez" constituye una marca de existencia.

Durante la última década del siglo XX, el filósofo y escritor francés Régis Debray (1997), trabajó en la elaboración de una teoría general sobre la transmisión cultural. Realizó un recorrido por la formación 
de las religiones que — piensa - son un campo de experimentación ejemplar para el estudio de la transmisión. Debray se pregunta cómo la comunidad judía conserva los mismos ritos, calendarios, salmodia, los mismos versículos con el mismo balanceo de hace tres mil años, igualmente, se interroga cómo la Iglesia católica conserva marcos de pensamiento y administración heredados desde la época de Constantinopla. El extenso tiempo histórico en que estas tradiciones han sobrevivido abre la pregunta sobre la efectividad de la transmisión. A partir de estas reflexiones, Debray introduce el concepto de mediología, es decir, no hay transmisión sin vehículo; los retransmisores desempeñan un papel fundamental en el proceso y en todo lo que media la producción de sentido. Para el caso del cristianismo, Debray responde:

Los discípulos de Jesús no pudieron soportar la decepción de su muerte, la esperanza pudo más, volvieron a verlo mentalmente con vida y supusieron que seguía viviendo en el Cielo [...] la generación de los apóstoles desapareció, pero no su creencia, y eso es lo sorprendente. Se transmitió a San Pablo de Tarso, por ejemplo, quien no conoció a Jesús durante su ministerio, pero que lo vio en el camino de Damasco. Y Pablo, convertido, supo convencer a otros, que a su vez formaron una cadena de época en época, de ciudad en ciudad. La fe cristiana se articula con soportes sólidos - reliquias, imágenes santas, Escrituras - que están menos destinados a propagar el recuerdo de los hechos pasados que la interpretación que testigos distantes, los supuestos y totalmente impersonales Mateo, Marcos, Lucas y Juan, dieron de ellos durante su vida (Debray, 1997, p. 36. Las cursivas son mías).

No hay palabras, ni pensamientos fundantes. La institución, supuestamente encargada de la retransmisión, inventa poco a poco su origen. Afirma Debray: "la recolección hace la herencia, no a la inversa", (1997, p. 38) Fueron los discípulos quienes hicieron la proclamación de Cristo; fue el emperador Constantino (s. IV) quien fungió como medio para la institucionalización del cristianismo; fue el movimiento cristiano el que inventó a Cristo, y no a la inversa. Es el ser humano quien crea a los dioses y, paradójicamente, está dispuesto a seguir su voluntad. Debray sostiene que el objeto de la transmisión no preexiste a la operación de su transmisión. 
Así, la religión, paradigma donde se advierte un largo trayecto de transmisión y retransmisiones inconscientes a través de la palabra oral de sus mediadores, nos enseña que es un fenómeno que va de la consecuencia a la causa, es decir, no hay principio fundante, sino que es $a$ posteriori que se asimila una idea, que no es la original, en el psiquismo.

\section{El papel de los mitos en el acto de transmisión inconsciente}

Sin prácticas de transmisión, una sociedad no puede sobrevivir, en tanto que esta provee a una nación de asideros culturales. A partir de este hecho, los mitos desempeñan un papel primordial en la conformación de costumbres, pautas de convivencia sean sociales o individuales. En definitiva, el mito remite al signo de diferenciación entre las especies, es decir, a la especificidad humana de la palabra, posee una función social en que se ponen en práctica los instrumentos de humanización.

Alfonso Reyes advierte que el mito, desde tiempos inmemoriales, ha educado a la gente; en Grecia, por ejemplo, el niño lo aprendía de los labios de la nodriza; el escolar lo practicaba en el texto homérico; el ciudadano lo volvía a encontrar en el teatro, vivificado y con una nueva intención (Reyes, 1962). Si el mito es importante en la educación de los hijos, particularmente en el acto de transmisión, es porque permite al sujeto realizar el recorrido del héroe de la narración. Con ello, preserva la emoción de la hazaña y desdeña el mensaje coagulado, tal como se presentaría en una fábula.

El mito - propiamente hablando- no es un relato que dé acceso a un saber en forma, lo valioso de este género literario, es que narra las peripecias, los obstáculos, los peligros a que se somete el héroe, siempre en pos de un objeto escondido. Por el rodeo narrativo que lo constituye, ilustra el posible camino de la transmisión, ya que para el oyente o el lector abre el camino de las interrogaciones, del suspenso, pues no se trata de ninguna manera de textos sagrados.

Como género literario, el mito presenta diferencias estructurales respecto de otros afines como la fábula, la leyenda o el cuento folklórico. Su contenido remite al origen imposible de historiar, por ejemplo: la creación del hombre, la invención de los grandes recursos humanos (el fuego, la agricultura...), etc. en realidad poco importa si tal acontecimiento sucedió o no. Tiene un carácter atemporal, aunque relata un evento que puede referirse tanto a un pasado, un presente, o a un futuro. 
Lévi-Strauss dice que los mitos poseen una estructura permanente, ${ }^{2}$ exhiben una estabilidad que no los hace maleable a las modificaciones que pudieran aportarse; no se hallan sometidos a la reinvención. Incluso el autor hace notar que, a pesar de las cuantiosas traducciones que pueda tener un mito a diferentes lenguas, este sigue conservando su esencia, contrariamente a lo que sucedería, por ejemplo, con la traducción de un poema.

Cornaz examina el papel del mito en la eficacia de la transmisión, ponderando su dimensión inconsciente, que muestra efectos en la subjetividad, de ahí la necesidad de considerar que no pueda ser contado por cualquiera. Para que exista la transmisión, es ineludible que alguien haya sido colocado en el lugar del Otro, quien será aquel que posea el privilegio de influir. Para demostrarlo, Cornaz parte del análisis de una fábula atribuida a Esopo $(620-560$ a. C.) y de su reescritura, realizada por Jean de la Fontaine (1621-1695): El labrador y sus hijos. El mito de Esopo es como sigue:

Estando un labrador muy cercano a la muerte, llamó a sus hijos y les dijo: hijos míos, antes que yo muera, deseo instruiros de todo, y por tanto os digo que dejo cuantos bienes poseo en nuestra viña; y así cuando quisiereis partirlos entre vosotros, buscadlos en ella y allí los hallaréis. Después de haber fallecido el padre, se fueron ellos a la viña a buscar los bienes que les había dicho, y creyendo hallar un tesoro, cavaron la viña con mucho afán, y no hallaron el tesoro que creían, y dio muchos frutos aquel año; al partirlos los hijos entre sí dijo uno de ellos: los frutos de la viña son sin duda el tesoro que nuestro padre nos ha dejado. (Esopo, 2007)

Aquí se ilustra lo que llama un acto de transmisión. El tema principal es el padre que hereda a sus hijos. El labrador sabe que morirá y desea que sus hijos le escuchen, pero también sabe que cuando enuncia claramente la intención que lo impulsa, no garantiza su transmisión; por lo tanto, deja a sus hijos el trabajo de descubrirlo y acepta el riesgo de

2 Para precisar este concepto, Lévi-Strauss (1958), lo asemeja a la ideología política de su país. Dice, por ejemplo, que la Revolución Francesa no solo es una secuencia de acontecimientos pasados, sino que también es un esquema dotado de una eficacia permanente que permite interpretar la estructura social de la Francia actual y los antagonismos que allí se manifiestan, y entrever los lineamientos de la evolución futura. Lévi-Strauss, C. (1958). Antropología estructural. España: Paidós Básica, p. 232. 
que la transmisión fracase. Sostiene Cornaz que la crudeza o crueldad edípica "rige la transmisión" (1994, p. 13).

En su organización metafórica, el mito no contiene una enseñanza o explicación, por el contrario, rebasa el entendimiento y se constituye como enigma que da lugar a multiplicidad de sentidos; preserva una verdad que, sin embargo, no es posible comunicar de generación en generación, pues nadie puede garantizar la transmisión del sentido de las palabras (Cornaz, 1994), pues hay una dimensión significante $\mathrm{e}^{3} \mathrm{y}$ no de significado. El mito no se muestra como enseñanza, sino que se presenta como enigma que cada sujeto debe descifrar y es, como dice Cornaz (1994), el camino posible de la transmisión.

Así, es fácil contraponer el mito con la fábula, que apunta a demostrar una verdad moral sintetizada, al final de la narración en forma de moraleja. La fábula no deja al lector realizar por sí mismo el trabajo de interpretación; sugiere la clave del código e intenta prevenir el malentendido. Este género interrumpe el trabajo de transmisión que el mito preserva, pues se circunscribe al "deber ser" de la enseñanza y a la univocidad del sentido del texto. En la fábula se anticipa "el fracaso de la comunicación" al no tomar en cuenta la subjetividad reinante y la esencia misma del lenguaje: su polisemia, metáforas y metonimias; en síntesis, su carácter significante. Entonces, el mito es la vía regia por la cual la transmisión se hace posible, el sujeto elaborará a posteriori significados que irán transformándose por las incidencias del tiempo, de sus personajes y por la continua apropiación de los conocimientos científicos de avanzada.

3 En apoyo a esta tesis están los planteos de Jacques Lacan quien retoma los instrumentos lingüísticos del esquema de Saussure (significante y significado) y los subvierte. ¿Qué es un significante? Lacan hablará de la lógica del significante en contraposición a toda teoría sobre el significado, a sistemas de interpretación, a toda argumentación, a toda sustancia. De hecho, si Lacan retoma el término de lógica es porque en sí misma desvaloriza al significado a través del juego de significantes, cuyo ejemplo clásico lo podemos encontrar en el silogismo. Aquí por lo tanto el significante no significa nada, pero tiene la particularidad de poder significar cualquier cosa a través de la asociación libre. ¿Por qué esta desvalorización del significado? ¿por qué esta preferencia por el significante que no significa nada, sino cualquier cosa. El valor de una palabra es con relación a su posición con respecto a otra. La filosofía parte clásicamente para sus preguntas sobre el sujeto sobre lo que es la esencia, el ser, la unidad, una especie de significado sobre las cosas. 


\section{La palabra oral y escrita en la transmisión}

La palabra oral es el vehículo primario y más eficaz de la transmisión. Es el medio por el cual el sujeto se apropia, se vincula con el Otro primordial y de la cultura. La madre sería el medio transmisor primario por excelencia por su poder deseante sobre el hijo, en la primera época de la vida del niño la palabra de la madre es ley y es a través de su propia castración que la función paterna y la representatividad del padre tomen su lugar. Howlet Marc, en el contexto del estudio de los ritos de iniciación pubertaria, advierte que una constante en estas ceremonias es la exclusión de la mujer en las prácticas iniciáticas. Sin embargo, los hombres que ofician hacen las veces de agentes de la mujer: "El oficiante, en posición de mujer, mediante el juego de la codificación ritual, le permite al sujeto oír a la única persona que sea susceptible de hablarle: su madre" (Howlet, 1981, p. 141).

En otra dimensión del asunto, Bernard This (1980), dice que es de la voz ese objeto-causa del deseo de donde proviene el encanto, pues la acogida del niño "es ante todo verbal" (p. 182). La experiencia inmediata no permite apreciar que el bebé percibe la voz humana in utero; percibe los sonidos, y más aún, reconoce los que son graves más fácilmente que los agudos por razones de estructura del oído interno; distingue perfectamente, los matices y las entonaciones de nuestra voz. Este descubrimiento, dice This (1980), permite apuntar a la voz como la liga más primitiva entre el bebé y la voz del Otro, especialmente, con la del padre en su tarea de permitir el acceso a lo simbólico. Destaquemos que la acogida del niño a este mundo es ante todo verbal. Posterior al nacimiento, "el balbuceo puede ser considerado como una tentativa, en ausencia del padre o de la madre, de reencontrar su voz" (p.118).

Otra es la función de la palabra escrita en el contexto de la transmisión; la escritura no es solamente un intento social por garantizar la transmisión del saber, por preservar la palabra de los muertos en una memoria que sobreviva a la palabra oral; de hecho, Cornaz piensa que la palabra escrita no está vinculada con la transmisión del saber, puesto que la escritura "es un procedimiento mnemotécnico cuya utilidad depende por completo del saber del lector" (1994, p. 106). No es posible convertir al sujeto en el depositario de los conocimientos. Lo escrito solo sirve para reavivar su recuerdo. Platón, en Fedro o del Amor, hace hablar a Sócrates sobre la escritura a través del mito de Theuth, el dios 
egipcio inventor, entre otras destrezas, de la escritura, la cual presentó ante el rey Thamus, quien gobernaba aquel país:

El rey Thamus respondió: ¡Oh artificioso Theuth! [...] padre que eres de las letras, por apego a ellas, les atribuyes poderes contrarios a los que tienen. Porque es olvido lo que producirán en las almas de quienes las aprendan, al descuidar la memoria, ya que, fiándose de lo escrito llegarán al recuerdo desde afuera, a través de caracteres ajenos, no desde dentro, desde ellos mismos y por sí mismos. No es pues un fármaco de la memoria lo que has hallado, sino un simple recordatorio. Apariencia de sabiduría es lo que proporcionas a tus alumnos, que no verdad. Porque habiendo oído muchas cosas sin aprenderlas, parecerá que tienen muchos conocimientos, siendo, al contrario, en la mayoría de los casos, totalmente ignorantes, y difíciles, además, de tratar porque han acabado por convertirse en sabios aparentes en lugar de sabios de verdad (Platón, 2001, p. 295. Las cursivas son mías).

También, podríamos preguntar: ¿por qué escribe un autor? Algo que no se agota en el decir, puede encontrar otros caminos de expresión que van desde la configuración del síntoma en el cuerpo o en el pensamiento, hasta su sustitución en la escritura. La escritura permite apalabrar aquello que atormenta al sujeto, en tanto que el escribiente se esfuerza por ordenar ideas, incluso aquello que no ha podido salir mediante la palabra oral. Miguel de Unamuno expresa que, cuando estaba escribiendo Amor y Pedagogía en el papel, se convertía en una experiencia torturadora, pero que de esta manera "creía librarse de su tortura y trasladarla al lector" (Unamuno, 1989, p. 21). Freud advierte, en un trabajo sobre Estudios sobre la histeria publicado en 1893, que Goethe "no termina con una vivencia hasta no tramitarla en la actividad poética; en él ese es el reflejo preformado de un afecto, y mientras no haya consumado éste, subsiste la excitación acrecentada penosa" (Freud, 1988, p. 218). Vladimir Nabokov sostiene: "Empezar a escribir un libro no tiene otro propósito que liberarse de él" (1991, p. 381).

Por otro parte, es de merecer nuestra consideración la obra dialógica de Platón, donde se pondera la palabra oral en el proceso de transmisión. Esta forma literaria sugiere que es en la relación con otros que se genera un saber. El arte de Platón dice Cornaz, "es borrarse para 
dejar que sus personajes, que Sócrates, ocupen todo el lugar" (1994, p. 106). La influencia socrática se deja entrever en todo momento, pues casi siempre el personaje central es Sócrates, en cuya boca pone Platón los resultados de la transmisión entre estos dos intelectuales.

No es tan solo el cuerpo de la obra total escrita a modo de diálogo, donde la palabra oral adquiere importancia. La manera como Platón introduce, por ejemplo, el Banquete, deja entrever una dimensión temporal de la transmisión de largo alcance, que apunta a la transformación del discurso. Lo acontecido en el Banquete es relatado a Glaucón, después de muchos años por un tal Apolodoro, amigo y discípulo de Sócrates, quien por cierto no asistió al banquete, puesto que él era aún muy joven cuando tuvo lugar la disertación sobre el amor. Apolodoro sabía los pormenores de esa conversación por un cierto Aristodemo, quien era entonces uno de los más apasionados de Sócrates, y quien sí se hallaba presente el día del simposio. A nuestra consideración, Platón escribe la entrada de este diálogo de manera tan embrollada para destacar lo que hay de trascendente en la transmisión oral. Para elogiar y analizar las cuestiones del amor pareciera irrelevante esta forma de iniciar el tema; sin embargo, el género del diálogo da a entender que la palabra oral ocupa el primer sitio.

La voz es primaria, es la palabra viva que proviene del Otro, la que nos inunda con sus deseos, torpezas, vociferaciones, bendiciones o maldiciones. No en balde la palabra que más pesa en nosotros es la de la madre: la historia de un chico, aquel que está antes del nacimiento en el discurso de los padres, que desde el comienzo no cesa de acompañarlo y de orientar su vida dentro de un "Tú eres aquello" sin escapatoria; de aquí se deduce que la verdad proviene del Otro. De este Otro recibimos las incertidumbres y las certezas de la vida; es a partir del Otro que construimos deseos y preguntas, y con lo que se enlaza la noción de destino.

\section{Modos de la transmisión}

¿Cómo aprendemos todo este bagaje cultural? ¿Acaso todo el cúmulo de la cultura se nos ha enseñado intencionadamente? Aquí, adquiere todo su valor la distinción entre lo transmitido y lo enseñado.

La transmisión en la cultura ocurre sin que medie expresa y deliberadamente una enseñanza. Philippe Meirieu afirma que el vínculo transgeneracional queda garantizado por "impregnación" (1998, p. 26), es decir, sin que se piense realmente en ello y sin que sea una acción 
ordenada y sistemática. En la vida cotidiana, por ejemplo, si se sabe tal o cual cosa en las familias, se conversa en las comidas con la frecuencia suficiente para que la transmisión se realice mediante un juego sutil de evocaciones y explicaciones. Como Edward Hall señala (según se cita en Peacock, 2001, p. 28), que la cultura es un "lenguaje silencioso". Las tradiciones y las convenciones son silenciosas en el sentido de que suelen ser inconscientes. Personas que dicen actuar de modo racional y que solo se rigen por consideraciones como la eficiencia, se guían inconscientemente por tradiciones rígidas penetrantes (Peacock, 2001), efecto de formaciones reactivas ${ }^{4}$ de pulsiones antisociales. Ello se evidencia en los usos y las costumbres de los distintos espacios y tiempos de la historia, en los comportamientos de los actores sociales y, particularmente, en el lenguaje en su versión pragmática.

En el contexto de la sociedad mexicana del siglo XIX, desde la visión extranjera de Madame Calderón de la Barca (1978), en su acervo epistolar que constituye su libro La vida en México, atestigua estas formas culturales que persisten aún en la actualidad y explican una parte de la subjetividad del mexicano. Las singulares fórmulas de cortesía y protocolos que aparecen como sintagmas cristalizados en el español de México expresan la relación que el sujeto mantiene con el Otro social, donde se evidencia lo que Legendre llama lo genealógico inconsciente: "nuestras prácticas sociales están impregnadas de vocabulario genealógico", dice. Así, en nuestro país, escuchamos el automatizado imperativo "mande", "para servirle a usted", "estoy a sus pies", "patrón", "güerita", "cómpreme, ya es el último", "cómpreme pa' que me dé la bendición", o los significantes "padrísimo", "desmadre" (únicos en el mundo), "hijo de...", "mi brother" "carnal"... Estos sintagmas transparentan en el habla la relación genealógica que se mantiene con el Otro social. Así, todo acto de transmisión está vinculado con los modos de hablar, sean estos parte de una pragmática cultural interiorizada, o que obedezcan a una particular intencionalidad inconsciente de un emisor. No cabe duda; como señala Legendre que "la transmisión fabrica la subjetividad"' (Legendre, 1985, p. 164).

4 Las formaciones reactivas son un mecanismo de defensa, junto a la regresión y a la represión; se producen regularmente dentro del yo del neurótico obsesivo y las discernimos como exageraciones de la formación normal del carácter. ( $c f r$. Freud, en inhibición, Síntoma y Angustia, escrito publicado por primera vez en 1926. p.110).

5 La subjetividad es una idea hoy día tan vilipendiada que hasta es peligroso su uso cotidiano, porque se apela a la objetividad. El termino "subjetivo" viene del latín subiectivus y significa 
En el marco de la constitución del sujeto del inconsciente, a partir de los significantes provenientes del Otro primordial y de las experiencias vividas en su entorno social, el material inconsciente se expresa en el habla más allá de cualquier intención comunicativa. Por ejemplo: en una entrevista a una madre cuyo hijo cursaba la educación básica, se le preguntó su opinión sobre la inclusión de contenidos de educación sexual en la escuela primaria. Su respuesta literal fue que "estaba bien, pero que no le vayan a hacer mucho daño". El enunciado contiene dos juicios: uno reflexivo y otro espontáneo, por lo tanto, este último inesperado. Esta segunda parte alusiva, indirecta, impensada, expresa aquello que esta mujer ha introyectado, es decir, una significación desafortunada sobre la sexualidad. Es en el habla cotidiana, en lo no reflexivo donde podemos encontrar lo transmitido inconsciente que gobierna nuestra subjetividad, no en el ámbito de la comunicación.

Meirieu señala que a falta de nada que compartir en la familia puede sobrevenir una inmolación de la transmisión cultural, pues encontramos, por ejemplo, estos adolescentes "bólido", sin raíces históricas, sin acceso a la palabra, dedicados por entero a satisfacer impulsos originales (1998). Igualmente, encontramos en ciertos barrios de la ciudad de México, niños jugando en la calle a ser narcotraficantes, persiguiéndose y matándose unos a otros.

\section{Educación y transmisión}

En el pensamiento educativo de Durkheim, vertido en 1922 en Educación y Sociología, encontramos los primeros rastros de cómo él consideraba la transmisión. Explica que en el hombre las aptitudes de todo tipo son demasiado complejas para encarnarse en nuestros tejidos y materializarse bajo la forma de predisposiciones orgánicas. De ahí se desprende que esas aptitudes no pueden transmitirse de una generación a otra por vías genéticas y afirma entonces que "es a través de la educación como se lleva a cabo la transmisión" $(1975$, p. 55). El autor dice que una vez trazados los fines de la educación queda por preguntarse

que "depende de otra cosa", tan simple como decir que el sujeto no es racional por naturaleza, sino que "depende de otra cosa" y en este caso es del inconsciente. Descubrimiento por demás revolucionario de Sigmund Freud que permite estudiar la subjetividad humana sobre todo en los momentos de decisión. Para la confrontación entre el inconsciente y la subjetividad sugiero la lectura del artículo de Rodrigo da Cunha Pereira (2015), intitulado "Derecho y psicoanálisis, la subjetividad en la objetividad en los actos y hechos jurídicos" en la revista Aequitas, Vol. 9, N. ${ }^{\circ}$. 
sobre los medios de acción eficaces para el evento, y propone el germen de la idea de la transmisión como análoga a la sugestión hipnótica. En sus propias palabras expresa:

En efecto, la sugestión hipnótica supone las dos condiciones siguientes:

1. El estado en el cual se encuentra el sujeto hipnotizado se caracteriza por su pasividad excepcional. La mente queda prácticamente en blanco; se ha producido una suerte de vacío en la conciencia; la voluntad está como paralizada. Por consiguiente la idea sugerida, al no tener que enfrentarse con ninguna idea opuesta, puede instalarse con un mínimo de resistencia.

2. [...] Para ello, hace falta que el magnetizador hable con tono de mando, con autoridad... $(1975$, p. 67)

Entonces, Durkheim piensa que todo depende del respeto que tiene el educador para con sus funciones, y de los alumnos considerados como tabulas rasa, donde la conciencia del educador pasa sin filtros a la conciencia del niño (1975). Se trata de que el educador-magnetizador, ejerza toda su influencia educativa por vía de la palabra y del gesto.

Desde un enfoque psicoanalítico, la transmisión cambia sustancialmente; es un fenómeno que ocurre desde y durante la crianza de los niños más allá de cualquier prescripción educativa, no es un asunto que se produzca por indicaciones directas, hábitos, sino que se gesta en una multitud de pequeños eventos inintencionados con una carga emocional furtiva y con las que el sujeto se siente identificado. Las alusiones, las pláticas informales, las bromas, las conversaciones sobre terceros, en las comparaciones con otras personas, la historia inconsciente de los padres, sus deudas, sus sueños, en las maldiciones, es el arsenal donde, finalmente, se revela el deseo del Otro.

La apercepción de aquello que nos gobierna psíquicamente es uno de los factores que hace que nos preciemos vanamente de una sensación de autodeterminación y que, en consecuencia, se privilegie la razón sobre las decisiones y el actuar cotidiano. Justamente, el gran valor histórico del fenómeno hipnótico en la prehistoria del psicoanálisis es haber revelado la dependencia del sujeto con un Otro inconsciente. Cuando Freud utilizaba la hipnosis como método terapéutico y de investigación, observaba cómo en los síntomas del paciente aparecía el 
lenguaje, cómo palabras provenientes del exterior quedaban atrapadas en el cuerpo. Lo que se actualiza en la hipnosis, sin recordar, es un hecho de discurso, un imperativo formulado por otra persona. El sujeto ignora sus propias determinaciones, las que emanan del Otro y se evidencia que el sujeto, que se cree fuente y origen de su decir y hacer, es el ejecutor de una orden que se le escapa.

Cada quien establece una determinada relación con ese Otro, que va perfilando el destino por el camino enigmático que es la transmisión. Así, la pregunta esencial para cada uno de nosotros es saber cómo somos afectados por ese deseo del Otro inconsciente. Lo transmitido viene del lugar del Otro operando de manera intangible en la conducta e interviniendo en nuestras decisiones y elecciones. Todo ello, dice Cornaz, va conformando el destino de cada quien, más allá de los bienintencionados proyectos de vida y de los apoyos externos. Lo transmitido, vía la transferencia, determina los actos del sujeto, su destino, sus cegueras, sus éxitos, a despecho de sus dotes innatas y de su segmento social, sin considerar el carácter o el sexo (Cornaz, 1994). Lo transmitido, sea desde la familia o desde el entorno social, conforma nuestra subjetividad y nos constituye como seres en la cultura; es aquello que hemos "introyectado" desde la cuna, anticipando la manera como participamos en el mundo.

Así, la transmisión es un mecanismo que interviene subrepticiamente en las relaciones intergeneracionales entre padres e hijos, tanto como en los avatares de la enseñanza y del aprendizaje; es un proceso paradójico: en realidad no se trata de aquello de lo que nosotros, en la función de padres o docentes se quiere comunicar, sino de lo que el sujeto aprende a pesar de la intencionalidad educativa. Es decir, del lugar que ocupa el inconsciente en el deseo tanto de enseñar como de aprender.

\section{La transmisión del conocimiento: un imposible}

Hace aproximadamente 2400 años Sócrates, en la pluma de Platón, había señalado la imposibilidad de la transmisión de conocimientos, cuestión que es muy frecuentemente escuchada hoy. En El Banquete de Platón (2001, p. 496), Sócrates dice:

Ven, Sócrates - dijo Agatón-, permite que esté lo más próximo a ti, para ver si puedo ser partícipe de los magníficos pensamientos que acabas de descubrir: porque tengo una plena certeza que 
has descubierto lo que buscabas, pues de otra manera no hubieras dejado el dintel de la puerta.

Cuando Sócrates se sentó, dijo:

- ¡Ojalá, Agatón, que la sabiduría fuese una cosa que pudiese pasar de un espíritu a otro, cuando dos hombres están en contacto, como corre el agua, por medio de una mecha de Lana, de una copa llena a una copa vacía!

Imaginemos por un instante que la transmisión de saberes fuera posible; sus implicaciones serían graves, pues la creación se extinguiría y la repetición, sin falla, tomaría su lugar. Esta imposibilidad en la transmisión del pensamiento y del conocimiento es la guardiana de la creación; el pensamiento no se trasmite, contiene un imposible, un indecible. Sócrates lo sabe bien; él no puede dar gusto a su anfitrión Agatón, ni tampoco a Alcibíades, quien quisiera arrebatarle su saber.

Lo que se aprende - más allá de toda intención de enseñar y más allá del querer aprender- es la transmisión. Esto hace que el proceso sea incontrolable; no hay garantías de que lo que se quiere enseñar pasará del otro lado como un fluido, ni tampoco sabemos si esto sería deseable.

Por otra parte, para que la transmisión de un saber tenga lugar es necesario toparse con la duda, y para que se me plantee una pregunta, me la tiene que esbozar un Otro. Confesar la propia ignorancia es una condición esencial, pero también es necesario que el Otro responda, y no cualquier cosa y no de cualquier manera. Quienquiera que acoja la confesión de tal ignorancia encarnará esta figura y supondrá ser portador de la pregunta; de lo contrario, no suscita eco, ninguna respuesta. Resulta imposible transmitir un saber con claridad, reducido al estatuto de mensaje; lo que se transmite, lo que produce saber es el enigma de una formulación.

La adquisición de un saber se efectúa en el marco de una transmisión en la que, quien aprende, aun cuando trabaja totalmente solo, responde a la palabra de algún Otro inconsciente, más allá de toda psicología cognitiva. Es la respuesta del sujeto a la palabra de Otro que él reconoce como dirigida a él. Por otro lado, el sujeto solo accede de manera indirecta y sin certificación posible a este pensamiento del Otro. 
Por último, es apreciable para este rubro los principios generales de la teoría constructivista del aprendizaje que ve este proceso más flexible, pues impulsa al aprendiente a construir nuevas ideas y conceptos de las propias experiencias a través de diversas estrategias de enseñanza-aprendizaje. Estos principios son acordes a esta idea sobre la imposibilidad de la transmisión de conocimientos.

\section{Transmisión y comunicación. Sus implicaciones en la enseñanza}

Aunque la transmisión y la comunicación son dos términos asociados y convergen en la movilización de la palabra, estos se distinguen entre sí, conservando su propia especificidad, su mismo mecanismo. En apoyo a esta diferenciación se presenta la figura 1, en donde se muestra, mediante un plano cartesiano, estos dos conceptos supraordenadores, los cuales inciden en la constitución social del sujeto y en su estructuración inconsciente.

Figura 1. Diferencias esenciales entre la comunicación y la transmisión

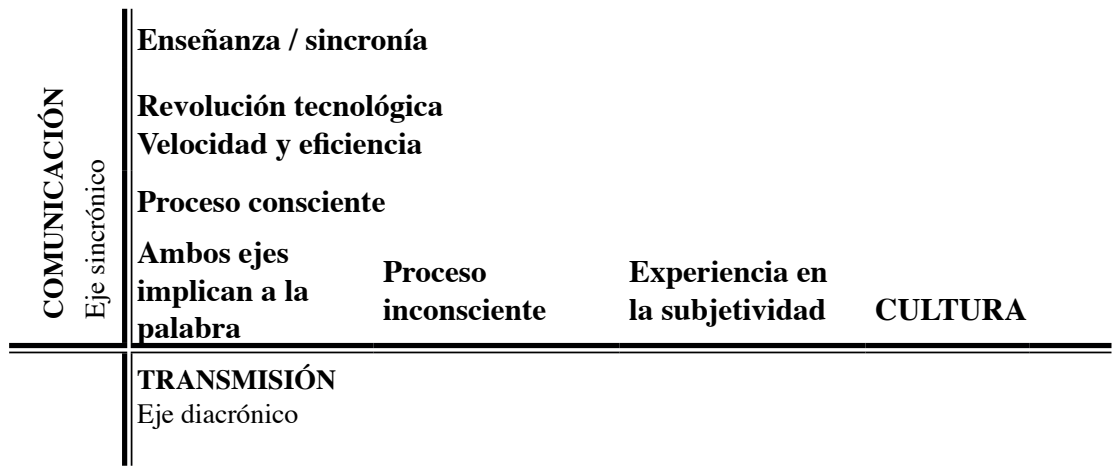

Fuente: Morales, M. (2011). Transmisión y apropiación de la ley en la Educación: Aportes del Psicoanálisis a la Pedagogía. Tesis de doctorado en Pedagogía por la UNAM.

En el eje diacrónico se puede reconocer la transmisión como un proceso mediante el cual una cultura se constituye y va transformándose a través del tiempo, en las formas de organización del poder, en la conservación milenaria de religiones, en las obras de arte, en las formas de comportamiento, etc. Es un tiempo lento, subjetivo de asimilación y acomodación que da como resultado, en lo social, la identidad cultural compartida, y en lo individual, la estructuración del sujeto del 
inconsciente. Lo que se juega aquí es la palabra vivida, supone la existencia de un legado propagado en comunidad a partir de un cuerpo de conocimientos, que adquiere consistencia a raíz de la construcción en una experiencia subjetiva, aspecto insoslayable que señala una de las diferencias entre transmitir y enseñar. La transmisión tiene esta cualidad de transporte en el tiempo que va vinculando "los vivos con los muertos" (Debray, 1997, p. 117) y demanda la creación de espacios propios inherentes a la naturaleza de su génesis.

En cambio, la comunicación se desarrolla en una dimensión sincrónica. Es un acontecimiento que atañe procesos conscientes, eficaces y veloces, toman el papel protagónico. Estamos en la época donde el tiempo cronológico es el parámetro de éxito, en ámbitos como el intercambio de información, terapias breves, la reducción de la curva del aprendizaje, la enseñanza, la producción de materiales pedagógicos más eficaces para la enseñanza, etc. El coadyuvante a esta misión se encuentra en el portentoso desarrollo tecnológico, la comunicación sucede a una velocidad vertiginosa lo cual a todos nos tiene maravillados, sin embargo, esta cuestión tiene sus efectos en la subjetividad, pues impide cualquier tipo de asimilación, de hecho, la celeridad de algún modo impide el aprendizaje. Aquí, el sujeto del inconsciente, en calidad de deseante, queda elidido en pos de la eficiencia y también, da lugar a nuevas patologías psíquicas, donde la predominancia es el vacío (cfr. Recalcati, 2003).

Es en este eje donde ubicamos a la enseñanza tal como sucede en el terreno áulico, donde predomina un saber asimilado a la ciencia. Es relativo que una persona asimile un conocimiento como consecuencia del proceso enseñanza-aprendizaje; por un lado, hay alguien que enseña sin que pueda garantizar el aprendizaje de un educando; por otro, existe la apropiación de un saber independientemente de lo que haya demostrado un maestro. En realidad, cada sujeto encuentra su propio camino, "se educa solo", dice Lacan (1991); va encontrando - bajo la égida de lo transmitido - el saber que se adhiere a su inconsciente. En su Presentación autobiográfica de 1920, Freud testimonia que el estudio de muchas disciplinas científicas le estaba vedado por la estrechez de sus dotes y alude a la verdad en la admonición de Mefistófeles en el Fausto de Goethe que alude: "en vano rondará usted de ciencia en ciencia; cada quien sólo aprende lo que puede aprender" (p. 9). Entendemos que lo que hay detrás del aprendizaje no es la enseñanza, es el 
deseo de saber algo en específico y no cualquier cosa, y este deseo tiene sus condiciones.

La transmisión no se confunde con la comunicación, sin embargo, actualmente, compiten entre ellas. La palabra que se juega en la comunicación está en el orden de la convención; es un proceso que sucede de "yo a yo"... Lo transmitido, como señala Debray, "no tiene las características del mensaje inicial" (1997, p. 46). Cornaz señala que el lugar de la transmisión es el de la comunicación imposible, pues fracasa precisamente, en el equívoco del sentido: transmitir no es comunicar. No está en el poder de alguien asegurarse que los otros piensen como él o compartan su saber. En realidad, el saber compartido solo existe en la ilusión del sentido común. Cornaz subraya que ninguna pedagogía vale si no toma en cuenta la realidad de este fracaso, o mejor dicho, de este imposible. Cualquier pedagogía que se funda en el éxito de la comunicación, que supone una comprensión entre el maestro y el alumno, es una superchería. La distancia entre lo que el maestro quisiera exigir que sus alumnos entiendan y lo que juzgan realmente cada uno de ellos es irreductible. Así, resulta imposible asegurarse de la transmisión del sentido.

El lenguaje no opera como un código que haría del ser humano un autómata: muestra su carácter polisémico en el juego significante, en el chiste, en la metáfora y metonimia, en la mentira, en el malentendido, por donde se manifiesta el deseo inconsciente. El inconsciente habla, pero no con el lenguaje de la comunicación, sino que se manifiesta en la falla de la palabra; esta tiene sentido y oculta el deseo prohibido desalojado de la conciencia. La palabra dicha sin pensar es la que transmite, porque ella está ligada a la verdad inconsciente. También, lo no dicho transmite, como ocurre con el eufemismo. La palabra de la comunicación es una palabra controlada y manipulada por lo que el "yo" quiere que piense el otro; es una palabra artificiosa que puede ser empleada en la autobiografía, en el consejo; es una palabra complaciente que se escenifica de un yo a otro yo; es una palabra seductora que puede dar lugar al autoengaño.

\section{Lo que organiza la transmisión: la castración del Otro}

La apercepción de aquello que nos gobierna psíquicamente es una de las razones que hace que nos preciemos vanamente de una sensación de autodeterminación, privilegiando la voluntad sobre las decisiones y el actuar cotidiano. El Otro inconsciente - tesoro del significante- es 
una de las instancias a las que estamos sujetados imperceptiblemente. La pregunta para cada uno de nosotros es saber cómo somos afectados por el deseo del Otro, pues lo transmitido es algo que proviene de este lugar que va perfilando nuestro destino.

Para que la transmisión tenga lugar, debe considerarse desde la postura de Lacan (1991) "la castración ${ }^{6}$ del Otro" (p. 136), que se representa en la grafía A (barrado por el significante). La castración del Otro implica que el ser que se está constituyendo perciba al Otro como incompleto, en tanto que no garantiza ni toda la verdad, ni todo el saber. Esto no es ni defecto, ni accidente: es una cuestión de lógica, y esta sostiene que la estructura ${ }^{7}$ nunca es completa. El Otro tachado es el lugar de la falta por donde el bebé se aliena en su deseo y se constituye como sujeto deseante. No somos nosotros quienes, con nuestra voluntad, accedemos al deseo, sino es desde la relación con el Otro que configuramos nuestras faltas. Esto implica que, si el infante no encuentra este intersticio en el Otro, no logra preguntarse qué soy ahí en el deseo del Otro y acceder posteriormente, él mismo a su propia castración (Lacan, 1991).

El Otro completo no puede incluir al niño en su deseo, pues no le hace falta nada, lo excluye de su discurso, por lo tanto, la transmisión se ve denegada. La película Spider (2002), del cineasta David Cronenberg, basado en la novela de Patrik Mcgrow, es una muestra de las consecuencias psíquicas de esta fatalidad. El chiste paradigmático "la madre del esquizofrénico" ofrece transparentemente lo que significa la no castración del Otro: una madre regala a su hijo dos corbatas, una roja y otra amarilla, el joven se pone la roja y ella le dice: ¡Qué! ¿No te gustó la amarilla? Acto seguido, el joven se quita la corbata que traía y se pone la amarilla. La madre contesta: ¡Qué! ¿No te gustó la roja? El muchacho ahora se pone las dos corbatas al mismo tiempo, y la madre contesta: ¡Qué! ¿Me quieres volver loca? Más allá de la imposibilidad

6 El término castración, en el ámbito psicoanalítico, no tiene una connotación peyorativa. La castración es función esencialmente simbólica, a saber, solo se concibe desde la articulación significante, [...] y de la que resulta que solo hay causa del deseo como producto de tal operación (Lacan, 1991).

7 El concepto de estructura se toma de la lógica de conjuntos, para definir un conjunto (de frutas), necesito un elemento diferente (verdura), que se define por -1, que no es el uno de la estructura. Es necesario el concepto de diferencia para definir la estructura. Para contar con la estructura, se necesita un conjunto y algo que dé legalidad a este conjunto, que será el Otro (A). El Otro da lugar a la estructura, legaliza la estructura (cfr. Lacan, clase del 18 de marzo 1970). 
de complacer a esta mujer, lo anterior evidencia una falla en el proceso de transmisión para el joven, no existe salida; no hay por dónde el sujeto pueda constituir su deseo, pues no encuentra la castración materna. Si el Otro está completo, el sujeto permanecerá sin ningún cambio de posición subjetiva, conservándose como objeto de goce del Otro. Si está tachado, habrá cambio de posición subjetiva y podrá advenir como sujeto deseante.

Contrariamente, puede suceder que la inconsistencia del Otro muestre tal fragilidad que no pueda sostener nada; se convierte en un otro semejante. Bajo estas condiciones, la transmisión igualmente, se ve denegada: un padre drogadicto, ante la indiferencia de su hijo de 12 años, suplicaba a este que por favor fuera su amigo, es obvio que un hijo no puede creer en su padre si este no sostiene una genealogía.

"La transmisión se organiza, entonces, a partir de la falta y la falla del Otro" (Kaës, et al. 1983, p. 24). Ya Freud lo había anunciado en 1914, en la Introducción del narcisismo, cuando afirma que el narcisismo del niño se apuntala sobre lo que falta a la realización de los sueños de deseo de los padres. Lacan elabora formalmente este tema, cuando desarrolla la metáfora paterna. ${ }^{8}$ La falta en el Otro es condición de la transmisión. La falta, "el no todo", es esencial para definir la estructura, lo que en psicoanálisis se llama castración simbólica (no imaginaria, no real). Lacan nunca hizo una clínica de los comportamientos, ni de los tipos ni de los síntomas, sino una clínica del sujeto con relación al deseo del Otro. La estructura clínica y la castración están ligadas, es la posición del sujeto en relación con la castración lo que está en juego. La castración se define como una operación simbólica que determina una estructura subjetiva.

Finalmente, al proceso de transmisión se liga la ética, tanto del lado del educador como de los educandos. Por lo regular, los educadores - sean padres de familia o docentes - no han tomado conciencia del poder que ejercen sobre sus educandos, y sus actos y palabras impactan, sin saber cómo, en la estructuración del sujeto. Aquí los modos de transmisión desempeñan un papel axial en el destino de cada sujeto.

8 El deseo de la madre, que dominaba totalmente al infante, es sustituido por el Nombre del Padre, el cual abrirá el campo de la significación fálica. El significante fálico es este tercer elemento que viene a romper la relación del gran Otro materno con el niño en tanto objeto $a$. La función paterna, en este contexto, es una función de separación que sostiene al sujeto a lo largo de su trabajo de inscripción en la problemática fálica. Esta función, en general, es sostenida por el padre, y es indispensable para que el destino del niño no sea perverso o psicótico. 
La paradoja que se crea en torno a la ética del educador es que nadie es dueño del sentido de las palabras, lo que implica que desconocemos, por estructura, lo que transmitimos. Cabe entonces preguntarse si es posible constituir una ética de aquello que no se sabe que se transmite.

Por otra parte, a lo que nos enfrentamos es a que la educación, por los canales convencionales que plantea la pedagogía, no modifica lo que ha sido transmitido, en tanto que son dos procesos que ocurren en diferentes registros. De ahí la importancia que adquiere el estudio de la transmisión para la pedagogía, pues como dice Cornaz (1994), educar es vérselas con la transmisión.

\section{Referencias}

Calderón de la Barca, M. (1978). La vida en México. Durante una residencia de dos años en ese país (1839-1841) Colección "Sepan cuantos..." N. ${ }^{\circ}$ 74. México: Porrúa.

Chemama, R. (1993). Dictionnaire de la Psychanalyse. Paris, Larousse. Cornaz, L. (1994). La escritura o lo trágico de la transmisión. México: Editorial Psicoanalítica de la Letra, A. C.

Da Cunha Pereira, R. (2015). Derecho y psicoanálisis la subjetividad en la objetividad en los actos y hechos jurídicos. Aequitas, 9 (9), 49-74.

Debray, R. (1997). Transmitir. Argentina: Manantial.

Durkheim, E. (1975). Educación y sociología. Barcelona: Península.

Esopo (2007). Fábulas completas. México: Letras Mayúsculas.

Freud, S. (1988). Presentación autobiográfica. En J. L. Etcheverry (Traduc.), Obras completas: Sigmund Freud (Vol. 24, pp. 1-66). Buenos Aires: Amorrortu. (Trabajo original en 1920).

(1988). Estudios sobre la histeria. En J. L. Etcheverry (Traduc.), Obras completas: Sigmund Freud (Vol. 2, pp. 1-311). Buenos Aires: Amorrortu. (Trabajo original publicado en 1893).

(1988). Introducción al narcisismo. En J. L. Etcheverry (Traduc.), Obras completas: Sigmund Freud (Vol. 13, pp. 65-98). Buenos Aires: Amorrortu. (Trabajo original publicado en 1914). (1988). Inhibición, síntoma y angustia. En J. L. Etcheverry (Traduc.), Obras completas: Sigmund Freud (Vol. 20, pp. 71-164). Buenos Aires: Amorrortu. (Trabajo original publicado en 1926).

Howlet, M. (1981). El concepto de iniciación. Revista Ornicar, 2, 129-147. 
Lacan, J. (1986). El seminario de Jacques Lacan libro 3 1955-1956. Las psicosis. Buenos Aires: Paidós.

Lacan, J. (1991). El seminario de Jacques Lacan libro 17. El reverso del psicoanálisis. Buenos Aires: Paidós.

Legendre, P. (1996). El inestimable objeto de la transmisión. Lecciones IV. México: Siglo XXI.

Lévi-Strauss, C. (1987). Antropología estructural. España: Paidós.

(2007). Mito y significado. España: Alianza Editorial.

Meirieu, P. (1998). Frankenstein educador. Barcelona: Laertes.

Morales, M. (2011). Transmisión y apropiación de la ley en la educación. Aportes del psicoanálisis a la pedagogía. México: UNAM.

Nabokov, V. (1991). Lolita. Barcelona: Anagrama.

Peacock, J. (2001). La lente antropológica. Luz fuerte, enfoque suave. México: Alianza Editorial.

Platón (2001). Diálogos de Platón. México: Porrúa.

Recalcati, M. (2003). La clínica del vacío. Anorexias, dependencias, psicosis. España: Síntesis.

Reyes, A. (1962). Obras completas. Religión griega. Mitología griega. Tomo XVI. México: FCE, Colección Letras Mexicanas.

This, B. (1980). El padre: acto de nacimiento. España: Paidós.

Unamuno, M. (1989). Amor y pedagogía. España: Colección Austral. 
